\title{
Borderline personality disorder and substance use disorders: an updated review
}

\author{
Timothy J. Trull*, Lindsey K. Freeman, Tayler J. Vebares, Alexandria M. Choate, Ashley C. Helle and Andrea M. Wycoff
}

\begin{abstract}
For decades, clinicians and researchers have recognized that borderline personality disorder (BPD) and substance use disorders (SUDs) are often diagnosed within the same person (e.g., (Gunderson JG. Borderline personality disorder: A clinical guide. Washington, D.C.: American Psychiatric Press, 2001; Leichsenring et al., Lancet 377:74-84, 2011; Paris J. Borderline personality disorder: A multidimensional approach. American Psychiatric Pub, 1994; Trull et al., Clin Psychol Rev 20:235-53, 2000)). Previously, we documented the extent of this co-occurrence and offered a number of methodological and theoretical explanations for the co-occurrence (Trull et al., Clin Psychol Rev 20:235-53, 2000). Here, we provide an updated review of the literature on the co-occurrence between borderline personality disorder (BPD) and substance use disorders (SUDs) from 70 studies published from 2000 to 2017, and we compare the co-occurrence of these disorders to that documented by a previous review of 36 studies over 15 years ago (Trull et al., Clin Psychol Rev 20:235-53, 2000).

Keywords: Borderline personality disorder, Substance use disorder, Alcohol use disorder, Comorbidity
\end{abstract}

\section{Background}

For decades, clinicians and researchers have recognized that borderline personality disorder (BPD) and substance use disorders (SUDs) are often diagnosed within the same person (e.g., [1-4]). Previously, we documented the extent of this co-occurrence and offered a number of methodological and theoretical explanations for the co-occurrence [4]. In this article, we provide an update on this co-occurrence by reviewing studies published between 2000 and 2017, inclusive, and we compare the co-occurrence rates between BPD and SUDs with our previous review. First, we briefly introduce the distinction between co-occurrence and comorbidity. Next, we provide some background and context on BPD symptoms and we highlight the conceptual and potential etiological overlap of SUDs and BPD. Third, we review and compare the data on the rates of co-occurrence between BPD and SUDs from the present and a previous review [4]. Finally, we discuss the conceptual and clinical implications of this co-occurrence to facilitate future research and treatment.

\footnotetext{
* Correspondence: trullt@missouri.edu

Department of Psychological Sciences, University of Missouri-Columbia, 210 McAlester Hall, Columbia, MO 65211, USA
}

\section{The issue of co-occurrence and comorbidity}

Psychiatric diagnostic comorbidity is a broad and complex issue, referring to both the co-occurrence of disorders within the same person and the covariation of disorders in a population [5]. Further, two distinct diseases or clinical disorders diagnosed in the same person represents "true" diagnostic comorbidity $[5,6]$. Establishing true comorbidity among syndromes within psychiatry is challenging given the relatively limited etiological information known, compared to many other conditions which are known to be distinct, and is easily influenced by diagnostic classification systems. Therefore, we focus our review on "co-occurrence," or two syndromes existing (i.e., overlapping) within the same individual at the same time, without assuming associations at the etiological level. BPD-SUD co-occurrence rates can still provide some clues as to potential shared and distinct etiology, traits, and course.

\section{Borderline personality disorder}

Borderline personality disorder (BPD), a severe personality disorder that develops by early adulthood, is characterized by emotion dysregulation, impulsive acts, disturbed interpersonal relationships, and suicidal and self-harm behaviors [7]. BPD is the most commonly diagnosed

(c) The Author(s). 2018 Open Access This article is distributed under the terms of the Creative Commons Attribution 4.0 International License (http://creativecommons.org/licenses/by/4.0/), which permits unrestricted use, distribution, and 
personality disorder in both inpatient and outpatient settings [2, 8], and recent estimates suggest that BPD is relatively prevalent in nonclinical populations as well (range 2-3\%) [9-11].

Although BPD is presented as a categorical disorder (i.e., present versus absent) in the DSM-5 [7], the evidence for dimensional approaches to pathological personality traits, and psychopathology more broadly, have a robust evidence base [12]. There are significant limitations with categorizing BPD, including heterogeneity within the categories, arbitrary cut-points, and high diagnostic co-occurrence $[13,14]$. Dimensional approaches are consistent with the current state of classification research in the field, and this is also true for BPD. For instance, BPD can be conceptualized as maladaptive variants of general personality traits from the Five Factor Model, primarily represented by high neuroticism, antagonism, and disinhibition [15]. This is largely consistent with the DSM Alternative Model (DSM-AM) representation of BPD [7]. However, given that the studies in this updated review utilized the categorical classification of BPD as is currently retained in DSM-5, we will focus on the categorical diagnoses of BPD (and SUDs). Nevertheless, we do discuss trait-based, dimensions that may be relevant to an understanding of the co-occurrence and comorbidity of BPD and SUDs.

Disorders with the highest rates of co-occurrence with BPD are mood, anxiety, substance use, and non-BPD personality disorders $[2,8,10]$. Considering both personality disorder and non-personality disorder co-occurrence, it appears that very few patients with a BPD diagnosis fail to meet criteria for another psychiatric diagnosis. These findings are consistent with the view that BPD represents a level of personality organization/dysfunction that cuts across existing diagnostic categories [16, 17]. Not surprisingly, substantial levels of impairment are associated with $\mathrm{BPD}$; individuals diagnosed with BPD are prone to attempt suicide, seek and utilize health care services, and report significant levels of impairment in personal, role, and social functioning $[1-3,10]$.

\section{Co-occurrence with substance use disorders (SUDs)}

As noted by Trull et al. [4], the co-occurrence of BPD and SUDs can be understood from both methodological and theoretical perspectives. First, the association between these two disorders in studies may be due to methodological artifacts. For example, chronic, excessive use of substances as well as problems due to excessive use are potential indicators of the BPD diagnosis (i.e., the BPD impulsivity criterion [7]). To address this potential artifact, researchers have examined co-occurrence independent from these shared features and established that substantial co-occurrence remains (e.g., see [18, 19]). This suggests that co-occurrence between the two disorders is not primarily a function of symptom overlap. Another potential methodological problem in assessing this co-occurrence is that many studies of substance-using samples are cross-sectional, and the active or withdrawal phases of substance use are characterized by features that resemble criteria of BPD (e.g., affective instability, interpersonal problems [7]). Thus, it is critical that assessors establish the experience of these BPD symptoms outside of any intoxication or withdrawal phase of substance use. Finally, the co-occurrence may be primarily due to a shared third variable that is etiologically relevant to both disorders (e.g., childhood trauma, family history of disinhibitory psychopathology). Therefore, it is crucial to assess individuals for relevant third variables to rule out this potential explanation. Relatedly, one disorder may be more likely to develop from the other (or vice versa) or the two disorders may reciprocally affect the maintenance of the other. Cross-sectional research designs cannot adjudicate the direction of causal influence; only longitudinal studies can address this issue.

Concerning theoretical influences on co-occurrence, both emotion dysregulation as well as impulsivity figure prominently in etiological accounts of both disorders [20]. For example, several criteria for BPD reference negative affectivity and affective instability (e.g., chronic feelings of emptiness, affective instability, anger dysregulation [7]). According to major theories of SUDs, emotion dysregulation also plays a role in the development of excessive substance use and problems related to use $[20,21]$. This may be most pronounced in later stages of addiction that are characterized by withdrawal and heightened negative affect [22]. Specifically, the use of substances may be an attempt to regulate negative emotions, through a negative reinforcement process, and coping with negative affect is one of the leading motivations relevant to substance use (e.g., [23]). As for impulsivity, this major personality feature of BPD can lead to a number of negative consequences including substance abuse and dependence. Etiological theories of SUDs also implicate impulsivity, especially in the early stages of addiction, and there is evidence that those higher in impulsivity may be more likely to experience tension reduction following substance use (i.e., a pharmacological vulnerability $[20,24])$. In addition to examining the co-occurrence of BPD and SUDs, the examination of underlying factors like emotion dysregulation and impulsivity that cut across these disorders can guide research in assessing shared etiology, treatment, and clinical course. With these issues in mind, we now turn to our updated review of the co-occurrence of BPD and SUDs.

\section{Method}

\section{Search protocol}

To obtain a current estimate of the co-occurrence between SUDs and BPD we conducted a comprehensive, 
systematic literature search in English language journals from 2000 to 2013 (inclusive), with an updated search for articles from 2014 to 2017 (inclusive). A review of the articles from the initial search has been published [25]. For both the initial and updated search, search terms combined ("borderline personality disorder" OR BPD) with any of the following: (substance OR "substance use disorder" OR abuse OR dependence OR alcohol OR "alcohol use disorder"). The term "structured interview" was an option to refine search results. Searches queried PubMed and PsycINFO. In the updated search, Google Scholar was also queried. We reviewed titles and abstracts and evaluated articles that were returned from searches. We included the 40 studies from the initial search (2000-2013 [25]) and another 30 studies from our updated search (2014-2017). See Fig. 1 for PRISMA Flow Diagram of study selection and exclusion process [26].

\section{Inclusion and exclusion criteria}

Inclusion criteria required each study to (a) use structured interviews using diagnostic criteria from the DSM-IV or DSM-5 to diagnose BPD, (b) use structured interviews using diagnostic criteria from the DSM-IV or DSM-5 to diagnose SUDs or sample adults in current treatment for
SUDs, and (c) present sample characteristics such that co-occurrence rates between BPD and SUDs could be calculated. We excluded studies that had constraints on samples such that other comorbidities were excluded in original samples (i.e., no current substance use, no bipolar disorder, no other Axis I disorders, etc.). We also excluded studies that recruited specifically for the co-occurrence between BPD and SUDs.

In the event that multiple articles reported on the same sample of participants, we included only the article with the largest sample size. Other articles with smaller subsets of the larger sample were excluded to avoid "double counting" such data. ${ }^{1}$ In total, data from 70 studies are reported here in Tables 1 and 2.

\section{Results}

Borderline personality disorder among persons with substance use disorders

Table 1 presents the rates of BPD diagnoses in those with SUDs, focusing on studies that include a SUD index sample that provides a count of individuals who were also diagnosed with co-occurring BPD. Studies are sorted and presented, in order, by setting: (a) solely inpatient; (b) solely outpatient; (c) forensic; (d) community; or (e) a combination of sampling methods.

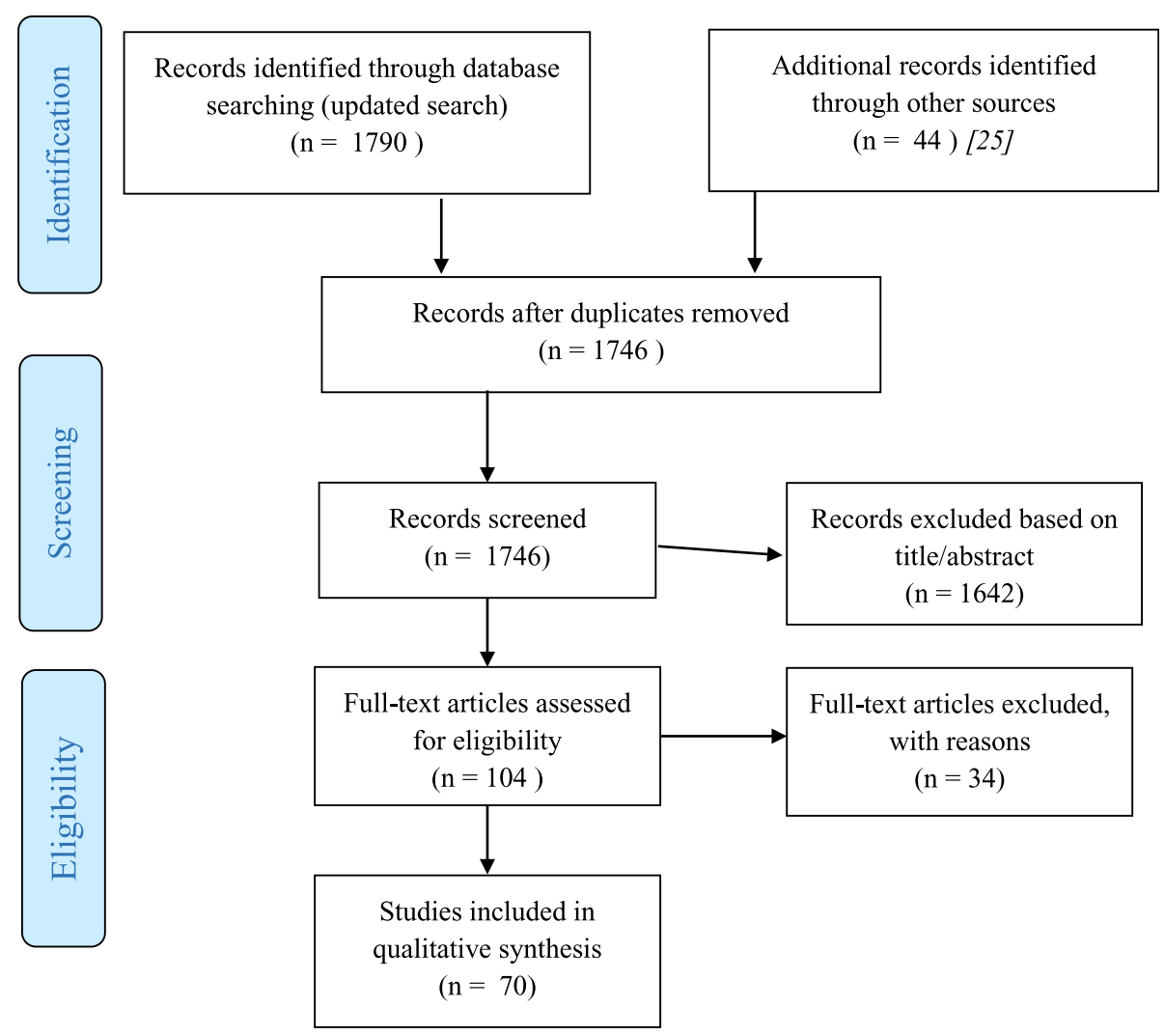

Fig. 1 PRISMA Flow Diagram 
Table 1 Prevalence of comorbid BPD in individuals with SUD

\begin{tabular}{|c|c|c|c|c|c|c|}
\hline Reference & Sample & $\begin{array}{l}\text { Diagnostic } \\
\text { Instrument }\end{array}$ & $\mathrm{N}$ with SUD & $\%$ female & $\begin{array}{l}\text { Mean } \\
\text { Age (SD) }\end{array}$ & $\mathrm{N}$ with BPD (\%) \\
\hline $\begin{array}{l}\text { Anestis, Gratz, Bagge, } \\
\text { \& Tull, } 2012 \text { [40] }\end{array}$ & Inpatient - C & $\begin{array}{l}\text { SCID-I/P; } \\
\text { DIPD-IV }\end{array}$ & 176 & 35.8 & $36.12(10.33)$ & $53(30.1)$ \\
\hline Bardeen et al., 2014 [41] & $\begin{array}{l}\text { Inpatient (cocaine } \\
\text { dependence) - C }\end{array}$ & DIPD-IV & 58 & 45 & $44.5(6.6)$ & $22(38.0)$ \\
\hline $\begin{array}{l}\text { Bornovalova et al., } \\
2008 \text { [42] }\end{array}$ & Inpatient - C & SCID & 76 & 32.9 & $42.2(8.2)$ & $24(31.6)$ \\
\hline $\begin{array}{l}\text { Bottlender, Preuss, } \\
\& \text { Soyka, } 2006 \text { [43] }\end{array}$ & $\begin{array}{l}\text { Inpatient (alcohol } \\
\text { dependence) - C }\end{array}$ & SCID-II & 237 & 18.1 & $42.0(--)$ & $42(17.9)$ \\
\hline $\begin{array}{l}\text { Dixon-Gordon, Tull, } \\
\text { \& Gratz, } 2014 \text { [44] }\end{array}$ & Residential SUD - C & $\begin{array}{l}\text { SCID-I; } \\
\text { DIPD-IV }\end{array}$ & 246 & 36.2 & $35.6(10.1)$ & $83(33.7)$ \\
\hline $\begin{array}{l}\text { Dunsieth et al., } 2004 \\
\text { [45] }\end{array}$ & $\begin{array}{l}\text { Residential (sex offenders } \\
\text { without paraphilias) - C }\end{array}$ & SCID & 26 & 0.0 & $39.0(6.1)$ & $4(15.4)$ \\
\hline Gonzalez, 2014 [46] & $\begin{array}{l}\text { Inpatient Detoxification } \\
\text { Unit - C }\end{array}$ & PAS & 53 & 45.3 & $38.66(8.45)$ & $11(21)$ \\
\hline Gratz \& Tull, 2010 [47] & $\begin{array}{l}\text { Inpatient (cocaine } \\
\text { dependence) - C }\end{array}$ & $\begin{array}{l}\text { SCID-IV; } \\
\text { DIPD-IV }\end{array}$ & 61 & 46.0 & $44.45(7.05)$ & $24(39)$ \\
\hline Kopetz et al., 2014 [48] & Residential SUD - C & $\begin{array}{l}\text { SCID-I; } \\
\text { SCID-II }\end{array}$ & 211 & 32 & $45(7.05)$ & $58(27.49)$ \\
\hline Krieger et al., 2016 [49] & Inpatient - C & $\begin{array}{l}\text { SCID-I; } \\
\text { SCID-II }\end{array}$ & 101 & 30.7 & $40.3(12.6)$ & $12(11.9)$ \\
\hline $\begin{array}{l}\text { Modestin et al., } 2001 \\
\text { [50] }\end{array}$ & $\begin{array}{l}\text { Inpatient (opioid } \\
\text { dependence) - C }\end{array}$ & SCID-II & 100 & 0.0 & $29.7(--)$ & $51(51.0)$ \\
\hline Preuss et al., 2001 [51] & $\begin{array}{l}\text { Inpatient (alcohol } \\
\text { dependence) - C }\end{array}$ & SCID & 135 & 20.7 & $41.8(8.8)$ & $23(17.0)$ \\
\hline Ross et al., 2003 [52] & Inpatient - C & SCID & 100 & 19.0 & $37.1(9.3)$ & $39(39.0)$ \\
\hline $\begin{array}{l}\text { Tull, Gratz, \& Weiss, } \\
2011 \text { [53] }\end{array}$ & Inpatient - C & $\begin{array}{l}\text { DIPD-IV; } \\
\text { SCID-I/P }\end{array}$ & 94 & 44.7 & $36.0(10.07)$ & $31(33.0)$ \\
\hline $\begin{array}{l}\text { Vergara-Moragues, } \\
\text { González-Saiz, Lozano, } \\
\text { \& García, } 2013 \text { [54] }\end{array}$ & $\begin{array}{l}\text { Inpatient (cocaine } \\
\text { dependence) - C }\end{array}$ & PRISM & 218 & 8.7 & - & $30(13.8)$ \\
\hline Webber et al., 2015 [55] & Inpatient - C & SCID-II & 235 & 53 & $30.06(8.41)$ & $120(51.3)$ \\
\hline $\begin{array}{l}\text { Yang, Liao, Wang, } \\
\text { Chawarski, \& Hao, } \\
2015 \text { [56] }\end{array}$ & $\begin{array}{l}\text { Inpatient (heroin } \\
\text { dependence) - C }\end{array}$ & $\begin{array}{l}\text { SCID-I; } \\
\text { SCID-II }\end{array}$ & 1002 & 30.04 & $33(6.8)$ & $226(22.6)$ \\
\hline $\begin{array}{l}\text { Zikos, Gill, \& Charney, } \\
2010 \text { [57] }\end{array}$ & Inpatient (AUDs) - C & $\begin{array}{l}\text { SCID-I; } \\
\text { SCID-II }\end{array}$ & 138 & 33.0 & $44(9.7)$ & $19(13.0)$ \\
\hline $\begin{array}{l}\text { Ball, } 2007 \text { [58]; Ball \& } \\
\text { Cecero, } 2001 \text { [59] }\end{array}$ & $\begin{array}{l}\text { Outpatient (opioid } \\
\text { dependence) - C }\end{array}$ & SCID-II & 78 & $\begin{array}{l}54.0 \text { (of those with } \\
\text { PDs) }\end{array}$ & $37.4(5.9)$ & $23(29.5)$ \\
\hline Barral et al., 2017 [60] & Outpatient - C & $\begin{array}{l}\text { SCID-I; } \\
\text { SCID-II }\end{array}$ & 937 & 23.5 & $37.83(10.05)$ & $128(13.7)$ \\
\hline $\begin{array}{l}\text { Becker, Añez, Paris, \& } \\
\text { Grilo, } 2010 \text { [61] }\end{array}$ & Outpatient (AUD-L) - L & S-DIPD-IV & 130 & 31.0 & $37.4(10.5)$ & $39(30.0)-C$ \\
\hline Casadio et al., 2014 [62] & Outpatient - C & SCID-II & 320 & 26.3 & $40.9(10.8)$ & $48(15)$ \\
\hline $\begin{array}{l}\text { Dammann et al., } 2017 \\
\text { [63] }\end{array}$ & $\begin{array}{l}\text { Outpatient (opioid } \\
\text { dependence) - C }\end{array}$ & SCID-II & 26 & 34.6 & $41(6.8)$ & $3(11.5)$ \\
\hline $\begin{array}{l}\text { DeMarce, Lash, Parker, } \\
\text { Burke, \& Brambow, } \\
2013 \text { [64] }\end{array}$ & Outpatient - C & $\begin{array}{l}\text { SCID-I; } \\
\text { SCID-II }\end{array}$ & 183 & 0.04 & $50.1(8.3)$ & $16(8.7)$ \\
\hline $\begin{array}{l}\text { Echeburua et al., } 2005 \\
\text { [65] }\end{array}$ & $\begin{array}{l}\text { Outpatient (alcohol } \\
\text { dependence) - C }\end{array}$ & $\begin{array}{l}\text { SCID-I } \\
\text { IPDE }\end{array}$ & 30 & 0.0 & - & $0(0.0)$ \\
\hline Echeburua, et al., 2007 [66] & $\begin{array}{l}\text { Outpatient (alcohol } \\
\text { dependence) - C }\end{array}$ & $\begin{array}{l}\text { SCID-l; } \\
\text { IPDE }\end{array}$ & 158 & 34.8 & $43.4(--)$ & $8(5.1)$ \\
\hline Hunter-Reel, Epstein, & Outpatient (AUD) - C & SCID-II & 102 & 100 & $45.05(9.19)$ & $6(5.88)$ \\
\hline
\end{tabular}


Table 1 Prevalence of comorbid BPD in individuals with SUD (Continued)

\begin{tabular}{|c|c|c|c|c|c|c|}
\hline Reference & Sample & $\begin{array}{l}\text { Diagnostic } \\
\text { Instrument }\end{array}$ & $\mathrm{N}$ with SUD & $\%$ female & $\begin{array}{l}\text { Mean } \\
\text { Age (SD) }\end{array}$ & $\mathrm{N}$ with BPD (\%) \\
\hline \multicolumn{7}{|l|}{$\begin{array}{l}\text { McCrady, \& Eddie, } \\
2014 \text { [67] }\end{array}$} \\
\hline Kidorf et al., 2015 [68] & $\begin{array}{l}\text { Outpatient (opioid } \\
\text { dependence) - C }\end{array}$ & $\begin{array}{l}\text { SCID-I; } \\
\text { SCID-II }\end{array}$ & 125 & 53.6 & $39.1(10.2)$ & $34(27.2)$ \\
\hline $\begin{array}{l}\text { Kok, de Haan, Wieske, } \\
\text { de Weert, \& de Jong, } \\
2017 \text { [69] }\end{array}$ & Outpatient - C & SIDP-IV & 102 & 19.6 & $40.7(10.8)$ & $2(2)$ \\
\hline Palmer et al., 2003 [70] & $\begin{array}{l}\text { Outpatient (opioid } \\
\text { dependence) - C }\end{array}$ & SCID & 107 & 53.0 & $43.1(6.6)$ & $40(37.4)$ \\
\hline Ralevski et al., 2007 [71] & $\begin{array}{l}\text { Outpatient (alcohol } \\
\text { dependence) - C }\end{array}$ & SCID & 225 & 2.7 & $47.0(--)$ & $68(30.2)$ \\
\hline $\begin{array}{l}\text { Zimmerman et al., } 2005 \\
\text { [72] }\end{array}$ & Outpatient (MIDAS) - C & $\begin{array}{l}\text { SCID-I; } \\
\text { SIDP-IV }\end{array}$ & 85 & - & - & $15(17.6)$ \\
\hline $\begin{array}{l}\text { Chapman \& Cellucci, } \\
2007 \text { [73] }\end{array}$ & Incarcerated - C & $\begin{array}{l}\text { TAAD; } \\
\text { SCID-II }\end{array}$ & $\begin{array}{l}58 \text { with Alcohol } \\
\text { Dependence } \\
73 \text { with Drug } \\
\text { Dependence }\end{array}$ & 100 & - & $\begin{array}{l}14 \text { (24.1) of those with } \\
\text { alcohol dependence } \\
21 \text { (28.8) of those with } \\
\text { drug dependence }\end{array}$ \\
\hline Grella et al., 2008 [74] & $\begin{array}{l}\text { Incarcerated (prison- } \\
\text { based substance abuse } \\
\text { treatment program) - C }\end{array}$ & SCID-II & 280 & 35.0 & $34.8(--)$ & $37(13.2)$ \\
\hline Mir et al., 2015 [75] & Incarcerated - C & $\begin{array}{l}\text { MINI; } \\
\text { SCID-II }\end{array}$ & 93 & 100 & - & $16(17)$ \\
\hline Fenton et al., 2011 [76] & Community (NESARC) - C & AUDADIS-IV & 613 & 32.5 & - & $\begin{array}{l}138 \text { (22.49) of those with } \\
\text { drug dependence }\end{array}$ \\
\hline $\begin{array}{l}\text { Whitbeck, Armenta, \& } \\
\text { Welch-Lazoritz, } 2015 \text { [77] }\end{array}$ & Homeless community - C & $\begin{array}{l}\text { CIDI; } \\
\text { DIPD-IV }\end{array}$ & 47 & 100 & $38.9(10.22)$ & $25(53.19)$ \\
\hline Comin et al., 2016 [78] & $\begin{array}{l}\text { Outpatient + Inpatient } \\
\text { Detoxification Unit } \\
\text { (cocaine dependence) - C }\end{array}$ & PRISM & 143 & 18.18 & $34.28(8.01)$ & $34(23.8)$ \\
\hline Daigre et al., 2015 [79] & Clinical $^{a}-\mathrm{C}$ & $\begin{array}{l}\text { EuropASI; } \\
\text { SCID-\|I }\end{array}$ & 512 & 24.1 & $38.8(10.1)$ & $66(12.9)$ \\
\hline Hasin et al., 2006 [80] & Inpatient \& outpatient - L & PRISM-IV & 285 & 46.0 & $36.3(8.8)$ & $56(19.5)-L$ \\
\hline $\begin{array}{l}\text { Malik, Chand, Marimuthu, } \\
\text { \& Suman, } 2017 \text { [81] }\end{array}$ & $\begin{array}{l}\text { Inpatient \& outpatient } \\
\text { (AUD) - C }\end{array}$ & $\begin{array}{l}\text { MINI; } \\
\text { SCID-II }\end{array}$ & 35 & 100 & $38.51(7.42)$ & $6(17)$ \\
\hline Ross et al., 2005 [82] & $\begin{array}{l}\text { Outpatient, residential, } \\
\text { community (heroin } \\
\text { dependence) - C }\end{array}$ & CIDI & 825 & 35.0 & $29.5(7.8)$ & $388(47.0)$ \\
\hline Rubio et al., 2007 [83] & $\begin{array}{l}\text { Inpatient \& outpatient } \\
\text { (alcohol dependence) - C }\end{array}$ & $\mathrm{SCID}$ & 247 & 0.0 & $40.3(--)$ & $29(11.7)$ \\
\hline Torrens et al., 2004 [84] & Inpatient \& outpatient - C & SCID & 105 & 31.0 & $33.3(7.7)$ & $7(6.7)$ \\
\hline Torrens et al., 2004 [84] & Inpatient \& outpatient - C & PRISM-IV & 105 & 31.0 & $33.3(7.7)$ & $12(11.4)$ \\
\hline Wapp et al., 2015 [85] & Inpatient \& outpatient - C & SCID-II; MINI & 1205 & 47.1 & $35.6(9.9)$ & $172(14.3)$ \\
\hline
\end{tabular}

NR denotes studies in which the raw count of individuals with BPD was not provided

$C$ Current diagnoses were reported. $L$ Lifetime diagnoses were reported

AUDADIS Alcohol Use Disorder and Associated Disabilities Interview Schedule, CIDI Composite International Diagnostic Interview, DIPD Diagnostic Interview for DSM-IV Personality Disorders, EuropASI European Addiction Severity Index, IPDE International Personality Disorder Examination, MINI Mini-International Neuropsychiatric Interview, PAS Personality Assessment Schedule, PRISM Psychiatric Research Interview for Substance and Mental Disorders, SCID Structured Clinical Interview for DSM-IV Disorders, SIDP-IV Structured Interview for DSM-IV Personality, TAAD Triage Assessment for Addictive Disorders

${ }^{a}$ Did not specify if the sample was inpatient or outpatient

\section{Across settings}

Overall, the co-occurrence rates between current SUDs ${ }^{2}$ and current BPD in these studies ranged from 0 to $53.19 \%$. Across all studies reporting current diagnoses, a total of 10,086 individuals were sampled with SUDs (or receiving treatment for addiction), and 2228 (22.1\%) of these individuals were also diagnosed with BPD. Please note that, throughout the rest of this article, we use the

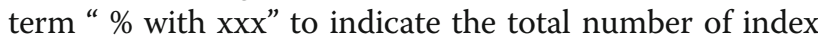
(co-occurring) cases divided by the total number of 


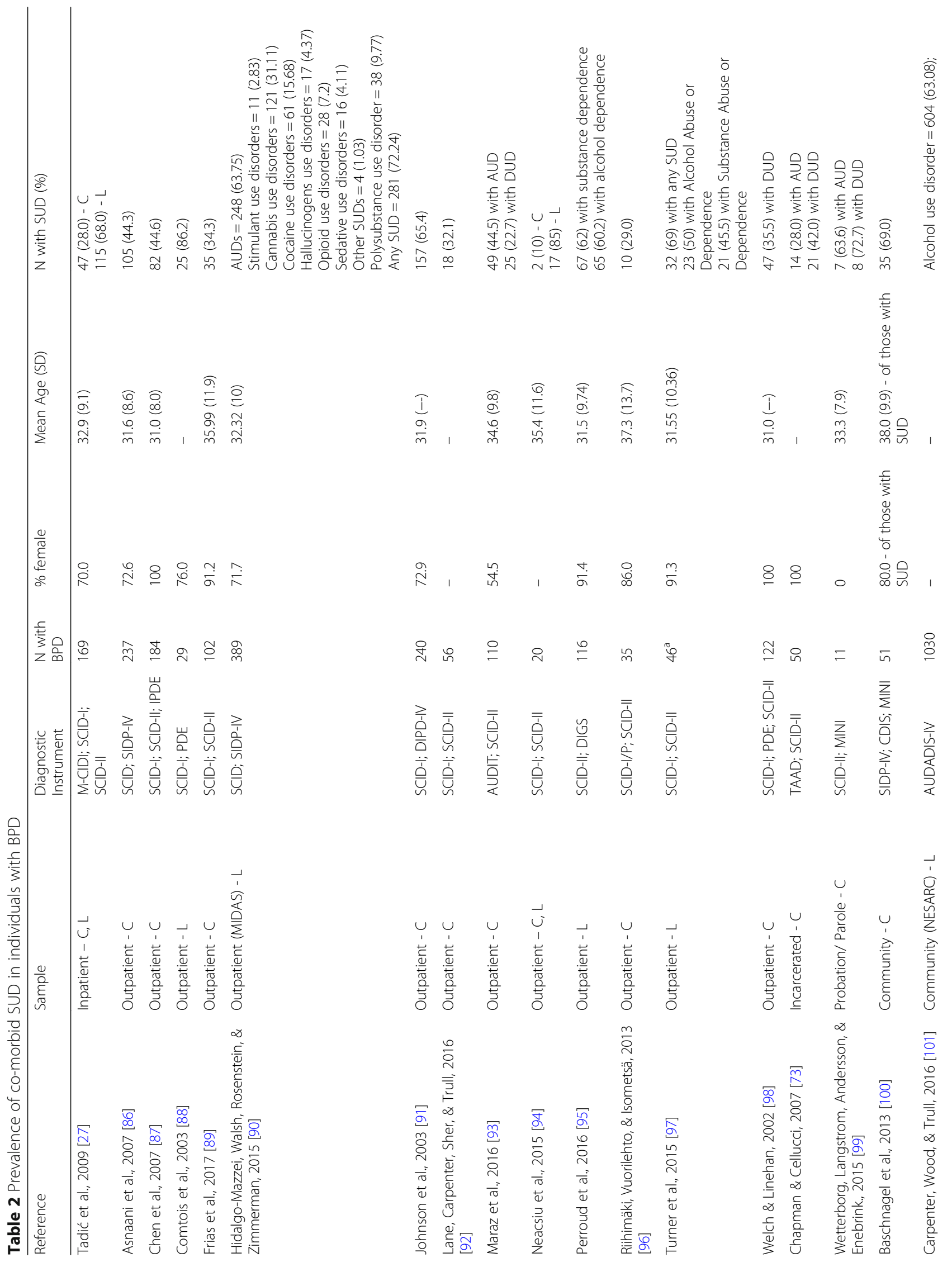


Trull et al. Borderline Personality Disorder and Emotion Dysregulation (2018) 5:15

Page 7 of 12

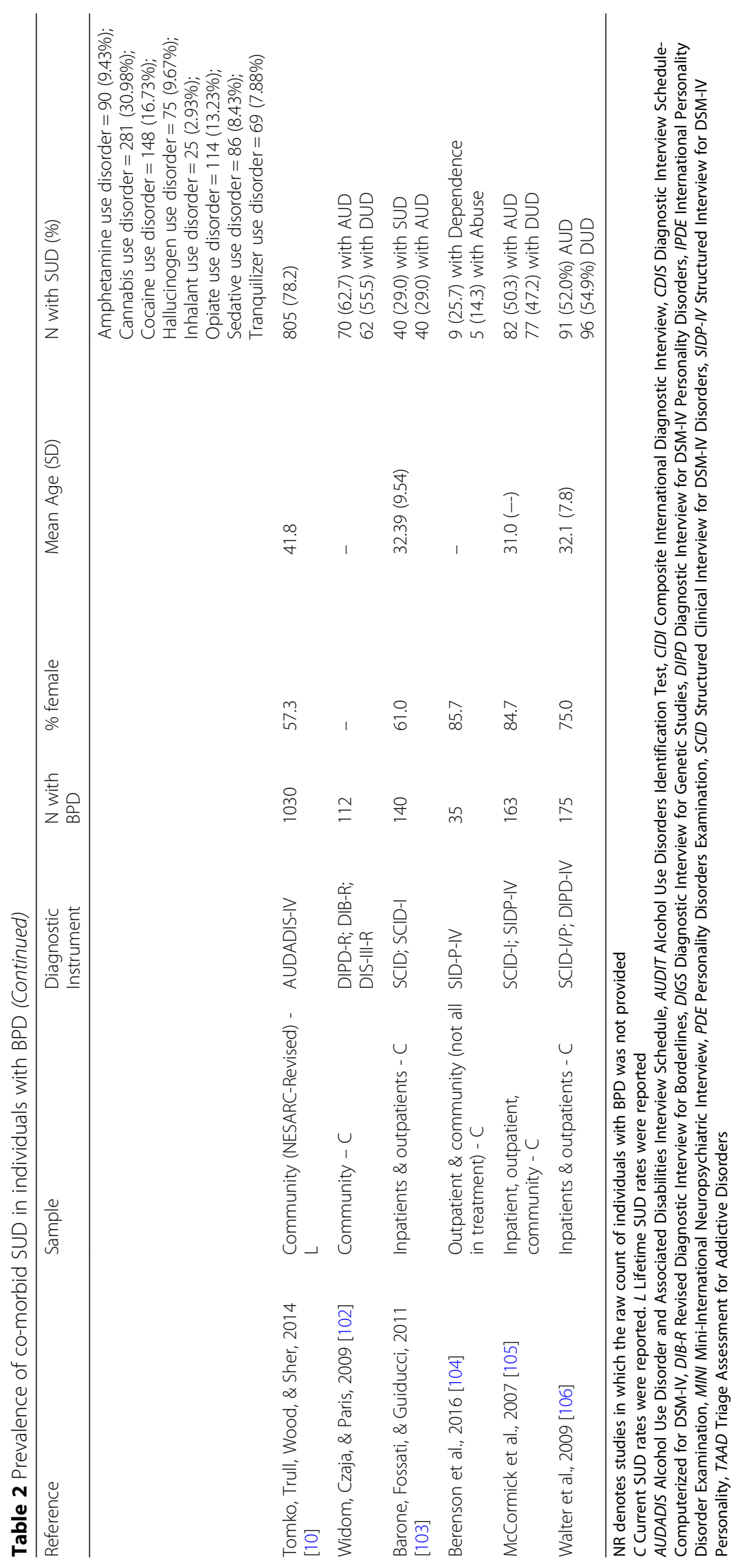


those receiving the other diagnosis, across all studies (i.e., a weighted average).

Ten studies specifically reported the co-occurrence rate of those with current BPD among individuals diagnosed with current AUD/alcohol dependence, ranging from 0 to $30.2 \%$ (total $n$ across studies $=1495 ; \%$ with $B P D=16.99 \%)$. Four studies sampled those with current cocaine dependence and reported a co-occurrence rate with current BPD between 13.8 and 39\% (total $n$ across studies $=631 ; \%$ with $B P D=22.03 \%)$. Seven studies sampled those with opioid dependence (including heroin dependence) and reported a co-occurrence rate with BPD between 11.5 and 51\% (total $n$ across studies $=2263$; \% with $B P D=33.80 \%)$.

\section{Within settings}

Eighteen of the studies reported in Table 1 recruited exclusively from inpatient or residential treatment settings. Out of the overall sample reported in these studies with a current SUD or currently in treatment for addiction $(n=3267), 26.7 \%$ of individuals also met criteria for current BPD. Of the 14 studies that recruited exclusively from outpatient settings (total $n=2478$ ), 15.8\% also met criteria for BPD. Eight of the studies reported in Table 1 recruited participants from a combination of different settings (inpatient, outpatient, and/or community). These studies were not counted in the estimates of the inpatient and outpatient samples alone. Of the 3177 total individuals with current SUDs sampled in these combined setting studies, $23.5 \%$ were also diagnosed with BPD. Finally, three studies reported the co-occurrence between current SUDs and current BPD in forensic samples (total $n=446 ; 16.6 \%$ with BPD) and two studies reported the current co-occurrence rates in community samples (total $n=660 ; 24.7 \%$ with BPD).

\section{Substance use disorders among persons with borderline personality disorder}

Table 2 presents the rates of SUDs in those with BPD, focusing on studies including a BPD index sample, as well as a count of individuals who were also diagnosed with concurrent SUDs. Once again, we organized studies by setting: solely inpatient, solely outpatient, forensic, community, and a combination of sampling methods.

\section{Across settings}

Co-occurrence rates between BPD and current SUDs reported in these studies (excluding those reporting on AUD specifically) ranged from 10 to $72.7 \%$ (\% with current SUD $=45.46 \%$ ). Rates between BPD and lifetime SUDs reported in these studies ranged from 45.5 to 86.2\% (\% with lifetime SUD $=75.28 \%$ ). Eleven studies reported the co-occurrence between BPD and AUD specifically, ranging from 28 to $63.6 \%$ for current AUD diagnoses (total $n$ across studies $=761 ; \%$ with current AUD $=46.39 \%$ ) and $50 \%$ to $63.7 \%$ for lifetime AUD diagnoses (total $n$ across studies $=1581$; $\%$ with lifetime AUD $=59.46 \%$ ). Finally, four studies reported the rates of a current drug use disorder (DUD; i.e., an SUD other than AUD) diagnosis in those with BPD, ranging from 28.57 to $72.73 \%$ (total $n$ across studies $=423$; \% with current DUD $=39.24 \%)^{3}$

\section{Within settings}

Only one study reported in Table 2 recruited exclusively from an inpatient setting [27]. Sixty eight percent of that sample met criteria for a lifetime SUD and $27.8 \%$ of the sample met criteria for a current SUD. Thirteen studies reported in Table 2 recruited from outpatient settings. Out of the overall combined sample in these studies reporting lifetime rates in outpatient settings $(n=600)$, $81.2 \%$ also met criteria for a lifetime SUD. Out of the overall combined sample in these studies reporting current diagnoses in outpatient settings $(n=1106)$, $48.8 \%$ also met criteria for a current SUD. Thirty four percent of the combined BPD sample in the two studies reporting from a forensic setting met criteria for a current AUD. Forty seven percent of the combined BPD sample in the two forensic studies met criteria for a current DUD.

Four of the studies reported in Table 2 recruited participants from a combination of different settings (inpatient, outpatient, and/or community). These studies were not counted in the estimates of the inpatient and outpatient samples alone. Three of these studies reported rates of AUD in BPD samples (combined $n=478$; $\%$ with a current AUD $=47.5 \%)$. Four of these studies reported rates of DUDs in BPD samples (combined $n=$ 513; \% with a current DUD $=44.3 \%$ ).

\section{Comparison to our previous review}

Using similar search strategies and inclusion/exclusion criteria, Trull et al. [4] reviewed 36 studies published over a ten-year period, from 1987 to 1997 inclusive. Across studies that reported rates of the general category of SUD (i.e., the particular substance was not specified), $57.4 \%$ of participants with BPD received a SUD diagnosis. Across those studies that provided rates of AUD (abuse or dependence) in BPD participants, 48.8\% met criteria for an alcohol use disorder. Finally, 38.0\% of participants with BPD met criteria for a DUD (abuse or dependence).

The comparable rates from the present review are: (1) $45.46 \%$ of participants with BPD received a current unspecified SUD diagnosis (i.e., the particular substance was not specified), and $75.28 \%$ of participants with BPD received a lifetime unspecified SUD diagnosis; (2) $46.39 \%$ of participants with BPD received a current AUD 
diagnosis, and $59.46 \%$ of participants with BPD received a lifetime AUD diagnosis; and (3) 39.24\% of participants with BPD met criteria for a current DUD.

Concerning co-occurrence rates of BPD diagnoses in participants with one or more SUDs (abuse or dependence), Trull et al. [4] reported that among those with unspecified SUD (i.e., single or multiple unspecified SUDs), $27.4 \%$ met diagnostic criteria for BPD. Focusing on specific, primary SUD diagnoses, $14.3 \%$ of those with alcohol abuse/dependence met criteria for BPD, $16.8 \%$ of those with cocaine abuse/dependence also received a BPD diagnosis, and $18.5 \%$ of those with opioid abuse/dependence met criteria for BPD. The comparable rates from the present review are: (1) among those with unspecified SUD, 22.1\% met diagnostic criteria for BPD, (2) $16.99 \%$ of those with alcohol use disorder met criteria for BPD, (3) $22.03 \%$ of those with cocaine dependence met criteria for BPD, and (4) $33.80 \%$ of those with opioid dependence met criteria for BPD.

\section{Conclusions}

As in our earlier review [4], our updated review of 70 studies demonstrates that BPD frequently co-occurs with SUDs, and these relations are apparent in both clinical populations and the general population. The estimates from our two reviews are fairly consistent, despite the range of populations sampled as well as the more recent time frame in the current review (i.e., 2000-2017). Approximately half of those with $\mathrm{BPD}$ also have at least one current SUD, most commonly AUD. Among those with a current SUD, approximately $25 \%$ also meet criteria for BPD. As for specific SUD diagnoses, those with current opioid, cocaine, and alcohol use disorder most frequently received a BPD diagnosis.

The research reviewed in this update maintained similar categorical, conceptualizations of BPD as the studies in the previous review. However, some methodological differences were present given the timeframe of the review periods. Specifically, the studies included in this updated review utilized DSM-IV or DSM-5 SUD criteria (i.e., different criteria and a different time-frame), whereas the previous review primarily included DSM-III and DSM-III-R criteria. Furthermore, the initial review primarily included studies reporting lifetime SUD diagnoses, while the current review included many studies reporting current SUD diagnoses.

As noted above, this co-occurrence can be understood in a number of ways from a theoretical perspective. Contemporary theories suggest that emotion dysregulation as well as impulsivity figure prominently in the development of both disorders [20, 21, 28, 29]. Furthermore, BPD-SUD co-occurrence may reflect common etiological processes with early expression of impaired impulse control and affective dysregulation in these conditions [20]. Concerning this purported common vulnerability, there is evidence from twin studies indicating that BPD and SUDs may share genetic influences. For example, studies have reported significant genetic correlations between borderline personality traits (BPTs) and substance use among adolescents and young adults [30], between BPTs and nicotine and cannabis use [31], between BPTs and alcohol, nicotine, and alcohol dependence [32], and between BPD symptoms and alcohol and cannabis use as well as alcohol and cannabis use disorders [33, 34]. Importantly, Few et al. [32] provided some evidence suggesting that the genetic correlation between BPD and SUDs may be due to shared personality traits such as neuroticism/affective instability. Findings such as these reinforce the utility of a dimensional perspective in pointing to shared, underlying etiological factors that may help to explain the observed co-occurrence of psychiatric disorders.

These findings, in concert with reviews of the phenotypic associations between BPTs, BPD and SUDs, suggest that the domains of emotion dysregulation/affective instability and of impulsivity might be targets of both etiological research on these conditions as well as treatment research that seeks to identify underlying vulnerabilities that serve to increase risk for these disorders. Unfortunately, despite the promise of current psychological treatments for BPD like Dialectical Behavior Therapy (DBT [35]), few randomized controlled trials have directly assessed the effects of treatment on SUD-related problems in those with BPD [36]. It is likely that to be successful in reducing substance abuse and substance-related problems, treatment may need to be modified to focus on and target specific influences in substance abuse that co-occurs with BPD [37].

The current shift towards examination and implementation of dimensional conceptualizations of psychopathology, including personality pathology, will likely aid in disentangling the relationship between BPD and SUD. Etiological research can be more targeted (i.e., common and distinct underlying traits/components), and treatments may be more trans-diagnostic in nature, rather than focused on heterogeneous categories for separate disorders.

Co-occurrence rates across studies should be considered within the context of the study methods. Methodological rigor and consistency is an important consideration when comparing prevalence rates and co-occurrence across studies and samples. Diagnostic classification can also greatly impact the variation in the "output" from all of the studies. Although we have given equal weight to study estimates without judging the methodological rigor of each, prevalence and co-occurrence rates can differ dramatically depending on how well diagnostic criteria and diagnoses are operationalized and assessed. Future studies should be 
very explicit in how diagnostic criteria and diagnoses are operationalized. For instance, is impairment a necessary component for judging a diagnostic criterion to be present? NESARC prevalence rates of personality disorder and substance use disorders differed significantly when criteria with impairment versus criteria without impairment were used to calculate the prevalence of personality disorder diagnoses $[11,38]$. When impairment was required for criteria to be considered for the diagnosis, the prevalence rates of PDs decreased, whereas the co-occurrence of many PDs (including BPD) and SUDs increased [11].

The question of whether SUDs are a cause or consequence of BPD cannot be answered definitively by our review of the existing research. However, because common genetic, personality, and early environmental influences predate overt substance use, it seems unlikely that PDs are simply secondary to substance use disorder. The effect of SUD on PD expression appears to be one of exacerbating PD symptomatology and, in turn, contributing to chronicity. This may be a transactional process at various levels of analysis; for instance, neuroadaptations of reward systems may occur as a result of chronic distress (associated with negative affectivity), thereby influencing the development of or risk for substance use [39]. This has important treatment implications in that clinicians must keep in mind the challenges present when planning and implementing treatment for those with both SUD and PD. It may be the case that variations on existing treatments or even new treatments are needed for this co-occurring condition. Regardless, prospective studies are needed to address the specific onset and course of the relationship between syndromes, as well as the exact transactional and temporal nature of these associations.

\section{Endnotes}

${ }^{1}$ Carpenter, Wood, \& Trull (2016) [101] and Tomko, Trull, Wood, \& Sher (2014) [10] used the same sample but differed in how SUDs were reported (i.e. reporting an overall rate of SUDs vs. reporting more specific SUDs), so both studies were included.

${ }^{2}$ Only one study reported in Table 1 recruited an index sample with lifetime (rather than current) substance use disorder (Becker, Añez, Paris, \& Grilo, 2010 [61]); the rate of BPD in that sample was $30 \%$. Similarly, one study reported the lifetime rate of BPD in the sample (Hasin et al., 2006 [80]), which was $19.5 \%$. These two studies are not included in any of the calculations in this section.

${ }^{3}$ Note that we did not aggregate the specific substance use disorders for the sample reported in Carpenter, Wood, and Trull (2016) [101] or the sample reported in Hidalgo-Mazzei et al. (2015) [90], since individuals may have received more than one substance use disorder diagnosis.

\section{Authors' contributions}

TJT, LKF, TJV, AMC, and AMW made substantial contributions to conception and design, and acquisition of data. TJT, LKF, TJV, AMC, ACH, and AMC analysis and interpretation of data; TJT, LKF, TJV, AMC, ACH, and AMC were involved in drafting portions of the manuscript and revising it critically for important intellectual content; and TJT, LKF, TJV, AMC, ACH, and AMC gave final approval of this version of the manuscript.

Ethics approval and consent to participate

Not applicable; review of published studies.

\section{Consent for publication}

Not applicable; review of published studies.

\section{Competing interests}

The authors declare that they have no competing interests.

\section{Publisher's Note}

Springer Nature remains neutral with regard to jurisdictional claims in published maps and institutional affiliations.

Received: 10 May 2018 Accepted: 3 September 2018

Published online: 19 September 2018

References

1. Gunderson JG. Borderline personality disorder: a clinical guide. Washington, D.C.: American Psychiatric Press; 2001.

2. Leichsenring F, Leibing E, Kruse J, New AS, Leweke F. Borderline personality disorder. Lancet. 2011;377:74-84.

3. Paris J. Borderline personality disorder: a multidimensional approach. Washington DC: American Psychiatric Pub; 1994.

4. Trull TJ, Sher KJ, Minks-Brown C, Durbin J, Burr R. Borderline personality disorder and substance use disorders: a review and integration. Clin Psychol Rev. 2000;20:235-53.

5. First MB. Mutually exclusive versus co-occurring diagnostic categories: the challenge of diagnostic comorbidity. Psychopathology. 2005;38:206-10.

6. Lilienfeld SO, Waldman ID, Israel AC. A critical examination of the use of the term and concept of comorbidity in psychopathology research. Clin Psychol Sci Pract. 1994;1:71-83.

7. American Psychiatric Association. Diagnostic and statistical manual of mental disorders. 5th ed. Arlington: American Psychiatric Publishing; 2013.

8. Widiger TA, Trull TJ. Borderline and narcissistic personality disorders. In: Adams H, Sutker P, editors. Comprehensive handbook of psychopathology. 2nd ed. New York: Plenum; 1993. p. 371-94.

9. Lenzenweger M, Lane M, Loranger A, Kessler R. Personality disorders in the National Comorbidity Survey Replication. Biol Psychiatry. 2007:62:553-64.

10. Tomko RL, Trull TJ, Wood PK, Sher KJ. Characteristics of borderline personality disorder in a community sample: comorbidity, treatment utilization, and general functioning. J Personal Disord. 2014;28(5):734-50.

11. Trull TJ, Jahng S, Tomko RL, Wood PK, Sher KJ. Revised NESARC personality disorder diagnoses: gender, prevalence, and comorbidity with substance dependence disorders. J Personal Disord. 2010;24(4):412-26.

12. Widiger TA. Dimensional models of personality disorder. World Psychiatry. 2007;6:79-83.

13. Clark LA. Assessment and diagnosis of personality disorder: perennial issues and an emerging reconceptualization. Annu Rev Psychol. 2007;58:227-57.

14. Widiger TA, Trull TJ. Plate tectonics in the classification of personality disorder. Am Psychol. 2007;62:71-83.

15. Saulsman LM, Page AC. The five-factor model and personality disorder empirical literature: a meta-analytic review. Clin Psychol Rev. 2004;23: 1055-85.

16. Kernberg O. Severe personality disorders. New Haven: Yale University Press; 1984.

17. Millon T. Disorders of personality: DSM-III Axis II. New York: Wiley; 1981.

18. Dulit RA, Fyer MR, Haas GL, Sullivan T, Frances AJ. Substance use in borderline personality disorder. Am J Psyc. 1990;147:1002-7.

19. Grilo CM, Martino S, Walker ML, Becker DF. Controlled study of psychiatric comorbidity in psychiatrically hospitalized young adults with substance use disorders. Am J Psyc. 1997;154:1305-7. 
20. Littlefield AK, Sher KJ. Personality and substance use disorders. In: Sher KJ, editor. Oxford handbook of substance use disorders, vol. 1. New York: Oxford; 2016. p. 351-74.

21. Conrod P, Nikolaou K. Annual research review: on the developmental neuropsychology of substance use disorders. J Child Psychol Psychiatry. 2016;57:371-94

22. Kwako LE, Momenan R, Litten RZ, Koob GF, Goldman D. Addictions neuroclinical assessment: a neuroscience-based framework for addictive disorders. Biol Psychiatry. 2016;80:179-89.

23. Cooper ML, Kuntsche E, Levitt A, Barber LL, Wolf S. Motivational models of substance use: a review of theory and research on motives for using alcohol, marijuana, and tobacco. In: Sher KJ, editor. The Oxford handbook of substance use disorders, vol. 1. New York: Oxford; 2016. p. 375-421.

24. Litten RZ, Ryan ML, Falk DE, Reilly M, Fertig JB, Koob GF. Heterogeneity of alcohol use disorder: understanding mechanisms to advance personalized treatment. Alc Clin Exp Res. 2015;39:579-84.

25. Trull TJ, Solhan MB, Brown WC, Tomko RL, Schaefer L, McLaughlin KD, Jahng S. Substance use disorders and personality disorders. In: Sher KJ, editor. The Oxford handbook of substance use disorders, vol. 2. New York: Oxford; 2016. p. $116-48$.

26. Moher D, Liberati A, Tetzlaff J, Altman DG. Preferred reporting items for systematic reviews and meta-analyses: the PRISMA statement. PLoS Med. 2009;6(7):e1000097.

27. Tadić A, Wagner S, Hoch J, Başkaya Ö, von Cube R, Skaletz C, ..., Dahmen N. Gender differences in axis I and axis II comorbidity in patients with borderline personality disorder. Psychopathology 2009;42:257-263.

28. Crowell SE, Beauchaine TP, Linehan MM. A biosocial developmental mode of borderline personality: elaborating and extending Linehan's theory. Psychol Bull. 2009;135:495-510.

29. Gunderson JG, Fruzzetti A, Unruh B, Choi-Kain L. Competing theories of borderline personality disorder. J Personal Disord. 2018;32:148-67.

30. Bornovalova MA, Hicks BM, lacono WG, McGue M. Longitudinal twin study of borderline personality disorder traits and substance use in adolescence: developmental change, reciprocal effects, and genetic and environmental influences. PD:TRT. 2013;4:23-32.

31. Distel MA, Trull TJ, de Moor MM, Vink JM, Geels LM, van Beek JH, et al, Borderline personality traits and substance use: genetic factors underlie the association with smoking and ever use of cannabis, but not with high alcohol consumption. J Personal Disord. 2012;26:867-79.

32. Few LR, Grant JD, Trull TJ, Statham DJ, Martin NG, Lynskey MT, Agrawal A. Genetic variation in personality traits explains genetic overlap between borderline personality features and substance use disorders. Addiction. 2014;109:2118-27.

33. Long EC, Aggen SH, Neale MC, Knudsen G, Krueger RF, South SC, et al. The association between personality disorders with alcohol use and misuse: a population-based twin study. Drug Alc Dep. 2017;174:171-80.

34. Gillespie NA, Aggen SH, Neale MC, Knudsen GP, Krueger RF, South SC, et al. Associations between personality disorders and cannabis use and cannabis use disorder: a population-based twin study. Addiction. 2018; https://doi. org/10.1111/add.14209.

35. Linehan M. Cognitive-behavioral treatment of borderline personality disorder. New York: Guilford press; 1993.

36. Lee NK, Cameron J, Jenner L. A systematic review of interventions for cooccurring substance use and borderline personality disorders. Drug Alc Rev. 2015;34:663-72.

37. Dimeff $L A$, Linehan MM. Dialectical behavior therapy for substance abusers. Addict Sci Clin Prac. 2008:4:39-47.

38. Grant BF, Stinson FS, Dawson DA, Chou SP, Ruan WJ, Pickering RP. Cooccurrence of 12-month alcohol and drug use disorders and personality disorders in the United States. Arch Gen Psychiatry. 2004;61:361-8.

39. Brady KT, Sinha R. Co-occurring mental and substance use disorders: the neurobiological effects of chronic stress. Am J Psychiatry. 2005;162:1483-93.

40. Anestis MD, Gratz KL, Bagge CL, Tull MT. The interactive role of distress tolerance and borderline personality disorder in suicide attempts among substance users in residential treatment. Compr Psychiatry. 2012;53:1208-16.

41. Bardeen JR, Dixon-Gordon KL, Tull MT, Lyons JA, Gratz KL. An investigation of the relationship between borderline personality disorder and cocainerelated attentional bias following trauma cue exposure: the moderating role of gender. Compr Psychiatry. 2014;55:113-22.

42. Bornovalova MA, Gratz KL, Daughters SB, Nick B, Delany-Brumsey A, Lynch $T R$, et al. A multi- modal assessment of the relationship between emotion dysregulation and borderline personality disorder among inner-city substance users in residential treatment. J Psychiatr Res. 2008:42:717-26.

43. Bottlender M, Preuss UW, Soyka M. Association of personality disorders with type a and type B alcoholics. Eur Arch Psychiatry Clin Neurosci. 2006;256:55-61.

44. Dixon-Gordon KL, Tull MT, Gratz KL. Self-injurious behaviors in posttraumatic stress disorder: an examination of potential moderators. J Affect Disord. 2014;166:359-67. https://doi.org/10.1016/j.jad.2014.05.033.

45. Dunsieth NW, Nelson EB, Brusman-Lovins LA, Holcomb JL, Beckman D, Welge JA, et al. Psychiatric and legal features of 113 men convicted of sexual offenses. J Clin Psychiatry. 2004;65:293-300.

46. Gonzalez C. Screening for personality disorder in drug and alcohol dependence. Psychiatry Res. 2014;217:121-3.

47. Gratz KL, Tull MT. The relationship between emotion dysregulation and deliberate self-harm among inpatients with substance use disorders. Cogn Ther Res. 2010;34:544-53.

48. Kopetz C, Pickover A, Magidson JF, Richards JM, Iwamoto D, Lejuez CW. Gender and social rejection as risk factors for engaging in risky sexual behavior among crack/cocaine users. Prev Sci. 2014;15:376-84.

49. Krieger DM, Benzano D, Reppold CT, Fialho PO, Pires GB, Terra MB. Personality disorder and substance related disorders: a six-month follow-up study with a Brazilian sample. J Bras Psiquiatr. 2016;65:127-34. https://doi. org/10.1590/0047-2085000000113.

50. Modestin J, Matutat B, Wurmle O. Antecedents of opioid dependence and personality dis- order: attention-deficit/hyperactivity disorder and conduct disorder. Eur Arch Psychiatry Clin Neurosci. 2001;251:42-7.

51. Preuss UW, Koller G, Bondy B, Bahlmann M, Soyka M. Impulsive traits and 5HT2A receptor promoter polymorphism in alcohol dependents: possible association but no influence of personality disorders. Neuropsychobiology. 2001:43:186-91.

52. Ross S, Dermatis H, Levounis P, Galanter M. A comparison between dually diagnosed inpatients with and without Axis $\|$ comorbidity and the relationship to treatment outcome. Am J Drug Alcohol Abuse. 2003:29:263-79.

53. Tull MT, Gratz KL, Weiss NH. Exploring associations between borderline personality disorder, crack/cocaine dependence, gender, and risky sexual behavior among substance-dependent inpatients. Person Disord Theory Res Treatment. 2011:2:209.

54. Vergara-Moragues E, González-Saiz F, Lozano OM, García AV. Psychiatric profile of three-month retention in cocaine-dependent patients treated in a therapeutic community. J Stud Alcohol Drugs. 2013;74:452.

55. Webber TA, Kiselica AM, Arango A, Rojas E, Neale MC, Mornovalova MA. Unidirectionality between borderline personality disorder traits and psychopathology in a residential addictions sample: a short-term longitudinal study. J Personal Disord. 2015;29:755-70. https://doi.org/10. 1521/pedi_2014_28_172.

56. Yang M, Liao Y, Wang Q, Chawarski MC, Hao W. Profiles of psychiatric disorders among heroin dependent individuals in Changsha, China. Drug Alcohol Depend. 2015;149:272-9. https://doi.org/10.1016/j.drugalcdep.2015.01.028.

57. Zikos E, Gill KJ, Charney DA. Personality disorders among alcoholic outpatients: prevalence and course in treatment. Can J Psychiatr. 2010;55:65-73.

58. Ball SA. Comparing individual therapies for personality disordered opioid dependent patients. J Personal Disord. 2007;21:305-21.

59. Ball SA, Cecero JJ. Addicted patients with personality disorders: traits, schemas, and presenting problems. J Personal Disord. 2001;15:72-83.

60. Barral C, Daigre C, Bachiller D, Calvo N, Ros-Cucurull E, Gancedo B, GrauLópez L, Ferrer M, Casas M, Roncero C. Severity factors associated with borderline personality disorders among misusers in an outpatient sample in Spain. J Addict Dis. 2017:36:93-6.

61. Becker DF, Añez LM, Paris M, Grilo CM. Exploratory factor analysis of borderline personality disorder criteria in monolingual Hispanic outpatients with substance use disorders. Psychiatry Res. 2010;178:305-8.

62. Casadio P, Olivoni D, Ferrari B, Pintori C, Speranza E, Bosi M, Belli V, Baruzzi L, Pantieri P, Ragazzini G, Rivola F, Atti AR. Personality disorders in addiction outpatients: prevalence and effects on psychosocial functioning. Subst Abuse. 2014:8:17.

63. Dammann G, Gerber H, Denier N, Schmid O, Huber C, Riecher-Rossler A, et al. The influence of comorbid personality disorder on patients in heroinassisted treatment: Pilot data on clinical outcome. Heroin Addict Relat Clin Prob. 2017; in press

64. DeMarce JM, Lash SJ, Parker JD, Burke RS, Grambow SC. Validity of the structured clinical interview for DSM-IV among veterans seeking treatment for substance use disorders. Int J Ment Heal Addict. 2013;11:546-56. 
65. Echeburua E, De Medina RB, Aizpiri J. Alcoholism and personality disorders: an exploratory study. Alcohol Alcoholism. 2005;40:323-6.

66. Echeburua E, De Medina RB, Aizpiri J. Comorbidity of alcohol dependence and personality disorders: a comparative study. Alcohol Alcoholism. 2007:42:618-22.

67. Hunter-Reel D, Epstein EE, McCrady BS, Eddie D. Personality disorders and the prediction of alcohol use outcomes for women: dimensional versus categorical classification. Addict Res Theory. 2014;22:176-80. https://doi.org/ 10.3109/16066359.2013.793314.

68. Kidorf M, King VL, Peirce J, Gandotra N, Ghazarian S, Brooner RK. Substance use and response to psychiatric treatment in methadone-treated outpatients with comorbid psychiatric disorder. J Subst Abus Treat. 2015;51: 64-9. https://doi.org/10.1016/j.jsat.2014.10.012.

69. Kok T, de Haan H, Wieske E, de Weert G, de Jong C. Screening for personality disorders in outpatient substance use disorder patients. Eur J Psychol Assess. 2017;33:166-72. https://doi.org/10.1027/1015-5759/a000282.

70. Palmer NB, Salcedo J, Miller AL, Winiarski M, Arno P. Psychiatric and social barriers to HIV medication adherence in a triply diagnosed methadone population. AIDS Patient Care STDs. 2003;17:635-44.

71. Ralevski E, Ball S, Nich C, Limoncelli D, Petrakis I. The impact of personality disorders on alcohol-use outcomes in a pharmacotherapy trial for alcohol dependence and comorbid Axis I disorders. Am J Addict. 2007;16:443-9.

72. Zimmerman M, Rothschild L, Chelminski I. The prevalence of DSM-IV personality disorders in psychiatric outpatients. Am J Psychiatr. 2005;162:1911-8.

73. Chapman AL, Cellucci T. The role of antisocial and borderline personality features in substance dependence among incarcerated females. Addict Behav. 2007;32:1131-45.

74. Grella CE, Greenwell L, Prendergast M, Sacks S, Melnick G. Diagnostic profiles of offenders in substance abuse treatment programs. Behav Sci Law. 2008;26:369-88.

75. Mir J, Kastner S, Priebe S, Konrad N, Strohle A, Mundt AP. Treating substance abuse is not enough: comorbidities in consecutively admitted female prisoners. Addict Behav. 2015;46:25-30. https://doi.org/10.1016/j.addbeh. 2015.02.016

76. Fenton MC, Keyes K, Geier T, Greenstein E, Skodol A, Krueger B, et al. Psychiatric comorbidity and the persistence of drug use disorders in the United States. Addiction. 2012:107:599-609.

77. Whitbeck LB, Armenta BE, Welch-Lazoritz ML. Borderline personality disorder and axis I psychiatric and substance use disorders among women experiencing homelessness in three U.S. cities. Soc Psychiatry Psychiatr Epidemiol. 2015:50:1285-91.

78. Comín M, Redondo S, Daigre C, Grau-López L, Casas M, Roncero C. Clinical differences between cocaine-dependent patients with and without antisocial personality disorder. Psychiatry Res. 2016;246:587-92.

79. Daigre C, Rodríguez-Cintas L, Tarifa N, Rodríguez-Martos L, Grau-López L, Berenguer $\mathrm{M}, \ldots$, Roncero $\mathrm{C}$. History of sexual, emotional or physical abuse and psychiatric comorbidity in substance-dependent patients. Psychiatry Res 2015;229:743-749.

80. Hasin D, Samet S, Nunes E, Meydan J, Matseoane K, Waxman R. Diagnosis of comorbid psychiatric disorders in substance users assessed with the psychiatric research interview for substance and mental disorders for DSMIV. Am J Psychiatr. 2006;163:689-96.

81. Malik K, Chand PK, Marimuthu P, Suman LN. Addiction severity and comorbidity among women with alcohol use disorders: a hospital-based study from India. Asian J Psychiatr. 2017;28:67-72. https://doi.org/10.1016/j.ajp.2017.03.028.

82. Ross J, Teesson M, Darke S, Lynskey M, Ali R, Ritter A, et al. The characteristics of heroin users entering treatment: findings from the Australian treatment outcome study (ATOS). Drug Alcohol Rev. 2005:24:411-8.

83. Rubio G, Jimenez M, Rodriguez-Jimenez R, Martinez I, Iribarren MM, Jimenez-Arriero MA, et al. Varieties of impulsivity in males with alcoho dependence: the role of cluster-B personality disorder. Alcohol Clin Exp Res. 2007;31:1826-32

84. Torrens M, Serrano D, Astals M, Perez-Dominguez G, Martin-Santos R. Diagnosing comorbid psychiatric disorders in substance abusers: validity of the Spanish versions of the psychiatric research interview for substance and mental disorders and the structured clinical interview for DSM-IV. Am J Psychiatr. 2004;161:1231-7.

85. Wapp M, van de Glind G, van Emmerik-van Oortmerssen K, Dom G, Verspreet $\mathrm{S}$, Jan Carpentier $\mathrm{P}, \ldots$... Moggi F. Risk factors for borderline personality disorder in treatment seeking patients with a substance use disorder: An international multicenter study. Eur Addict Res 2015:21:188194. doi: https://doi.org/10.1159/000371724.
86. Asnaani A, Chelminski I, Young D, Zimmerman M. Heterogeneity of borderline personality disorder: do the number of criteria met make a difference? J Personal Disord. 2007;21:615-25.

87. Chen EY, Brown MZ, Lo TTY, Linehan MM. Sexually transmitted disease rates and high-risk sexual behaviors in borderline personality disorder versus borderline personality disorder with substance use disorder. J Nerv Ment Dis. 2007:195:125-9.

88. Comtois KA, Russo J, Snowden M, Srebnik D, Ries R, Roy-Byrne P. Factors associated with high use of public mental health services by persons with borderline personality disorder. Psychiatr Serv. 2003;54:1149-54

89. Frias A, Navarro S, Palma C, Farriols N, Aliaga F, Salvador A, ..., Solves L. Early maladaptive schemas associated with dimensional and categorical psychopathology in patients with borderline personality disorder. Clin Psychol Psychother 2017;1-12. doi: https://doi.org/10.1002/cpp.2123

90. Hidalgo-Mazzei D, Walsh E, Rosenstein L, Zimmerman M. Comorbid bipolar disorder and borderline personality disorder and substance use disorder. J Nerv Ment Dis. 2015;203:54-7. https://doi.org/10.1097/NMD. 0000000000000235

91. Johnson DM, Shea MT, Yen S, Battle CL, Zlotnick C, Sanislow CA, et al. Gender differences in borderline personality disorder: findings from the collaborative longitudinal personality disorders study. Compr Psychiatry. 2003;44:284-92.

92. Lane SP, Carpenter RW, Sher KJ, Trull TJ. Alcohol craving and consumption in borderline personality disorder: when, where, and with whom. Clin Psychol Sci. 2016;4:775-92. https://doi.org/10.1177/2167702615616132.

93. Maraz A, Ando B, Rigo P, Harmatta J, Takach G, Zalka Z, ..., Demetrovics Z. The two-faceted nature of impulsivity in patients with borderline personality disorder and substance use disorder. Drug Alcohol Dependence 2016;163: 48-54. doi: https://doi.org/10.1016/j.drugalcdep.2016.03.015.

94. Neacsiu AD, Herr NR, Fang CM, Rodriguez MA, Rosenthal MZ. Identity disturbance and problems with emotion regulation are related constructs across diagnoses. J Clin Psychol. 2015;71:346-61.

95. Perroud N, Zewdie S, Stenz L, Adouan W, Bavamian S, Prada P, ... PaoloniGiacobino A. Methylation of serotonin receptor $3 \mathrm{~A}$ in ADHD, borderline personality, and bipolar disorders: link with severity of the disorders and childhood maltreatment. Depress Anxiety 2016;33:45-55.

96. Riihimäki K, Vuorilehto M, Isometsä E. Borderline personality disorder among primary care depressive patients: a five-year study. J Affect Disord. 2013;155:303-6.

97. Turner BJ, Dixon-Gordon KL, Austin SB, Rodriguez MA, Rosenthal MZ, Chapman AL. Non-suicidal self-injury with and without borderline personality disorder: differences in self-injury and diagnostic comorbidity. Psychiatry Res. 2015;230:28-35.

98. Welch SS, Linehan MM. High-risk situations associated with parasuicide and drug use in borderline personality disorder. J Personal Disord. 2002;16:561-9.

99. Wetterborg D, Langstrom N, Andersson G, Enebrink P. Borderline personality disorder: prevalence and psychiatric comorbidity among male offenders on probation in Sweden. Compr Psychiatry. 2015;62:63-70. https://doi.org/10. 1016/j.comppsych.2015.06.014.

100. Baschnagel JS, Coffey SF, Hawk LW, Jr., Schumacher JA, Holloman G. Psychophysiological assessment of emotional processing in patients with borderline personality disorder with and without comorbid substance use. Person Disord Theory Res Treat 2013:4:203.

101. Carpenter RW, Wood PK, Trull TJ. Comorbidity of borderline personality disorder and lifetime substance use disorders in a nationally representative sample. J Person Disord. 2016;30:336-50. https://doi.org/10.1521/pedi_2015_29_197.

102. Widom CS, Czaja SJ, Paris J. A prospective investigation of borderline personality disorder in abused and neglected children followed up into adulthood. J Personal Disord. 2009;23:433-46.

103. Barone L, Fossati A, Guiducci V. Attachment mental states and inferred pathways of development in borderline personality disorder: a study using the adult attachment interview. Attach Hum Dev. 2011;13:451-69.

104. Berenson KR, Gregory WE, Glaser E, Romirowsky A, Rafaeli E, Yang X, Downey G. Impulsivity, rejections sensitivity, and reactions to stressors in borderline personality disorder. Cogn Therapy Res. 2016;40:510-21. https:// doi.org/10.1007/s10608-015-9752-y.

105. McCormick B, Blum N, Hansel R, Franklin JA, St. John D, Pfohl B, et al. Relationship of sex to symptom severity, psychiatric comorbidity, and health care utilization in 163 subjects with borderline personality disorder. Compr Psychiatry. 2007;48:406-12.

106. Walter M, Gunderson JG, Zanarini MC, Sanislow CA, Grilo CM, McGlashan TH, ..., Skodol AE. New onsets of substance use disorders in borderline personality disorder over 7 years of follow-ups: findings from the collaborative longitudinal personality disorders study. Addiction 2009;104:97-103. 